1 Mechanisms of life-course socioeconomic inequalities in adult systemic

2 inflammation: findings from two cohort studies

3 Cristian Carmeli', Johan Steen ${ }^{2}$, Dusan Petrovic', Benoît Lepage ${ }^{3}$, Cyrille Delpierre ${ }^{4}$, Michelle $4 \quad$ Kelly-Irving ${ }^{4}$, Murielle Bochud', Mika Kivimäki ${ }^{5}$, Paolo Vineis ${ }^{6}$, Silvia Stringhini ${ }^{1,7}$

$6 \quad$ 'Center for Primary Care and Public Health (Unisanté), University of Lausanne, Switzerland

$7 \quad{ }^{2}$ Department of Intensive Care, Ghent University Hospital, Belgium

$8 \quad$ 3UMR LEASP, Université de Toulouse III, UPS, Inserm, Toulouse, France

9 IINSERM, UMRI 027, Toulouse, France, and Université Toulouse III Paul-Sabatier, Toulouse,

10 France

${ }^{5}$ Department of Epidemiology and Public Health, University College London, London, UK

${ }^{6}$ MRC-PHE Centre for Environment and Health, School of Public Health, Imperial College London, W2 IPG UK

${ }^{7}$ Unit of Population Epidemiology, Division of Primary Care, Geneva University Hospitals

\title{
Correspondence:
}

Dr. Cristian Carmeli

\section{E-mail: cristian.carmeli@unisante.ch}

Tel: +4 I 2 I 3147374 
This work was supported by the European Commission [grant Horizon 2020 number 633666] and the Swiss State Secretariat for Education, Research and Innovation SERI. The SKIPOGH study was supported by a grant from the Swiss National Science Foundation [grant number 33CM30-124087]. The CoLaus/PsyCoLaus study was and is supported by research grants from GlaxoSmithKline, the Faculty of Biology and Medicine of Lausanne, and the Swiss National Science Foundation [grant numbers 3200B0-I05993, 3200B0-II8308, 33CSCO-I2266I, 33CS30-I39468, and 33CS30-I4840I]. MK is supported by NordForsk, Academy of Finland (grant number 3I I492) and Helsinki Institute of Life Science. The funding sources had no involvement in the study design, data collection, analysis and interpretation, writing of the report, or decision to submit the article for publication.

None. 
Disadvantaged socioeconomic conditions in childhood heighten systemic inflammatory levels in adulthood; however, life-course mechanisms underlying this association are largely unknown. In the present observational study, we investigated the roles of adulthood socioeconomic and lifestyle factors in mediating this association.

Participants were from two prospective Swiss population-based cohorts $(\mathrm{N}=5,152$, mean age 60 years). We estimated the total effect of paternal occupational position on adult heightened systemic inflammatory levels (C-reactive protein $>3 \mathrm{mg} / \mathrm{L}$ ), and the indirect effects via adulthood socioeconomic positions (SEPs: education and occupational position), financial hardship, and lifestyle factors (body mass index, smoking status, physical inactivity, and alcohol consumption). We estimated odds ratio (OR) and proportion mediated using counterfactual-based mediation models. Individuals whose father had a low occupational position had an OR of I.5I [95\% confidence interval (CI): I.25, I.84] for heightened inflammation compared to their more advantaged counterparts. This was jointly mediated (33 [95\% Cl: 14, 69]\%) by adulthood SEPs, whereby the pathway through education followed by occupational position mediated $30[95 \% \mathrm{Cl}: \mathrm{II}, 64] \%$, while the pathway via occupational position only mediated $3[95 \% \mathrm{Cl}:-4,13] \%$. Individuals with the lowest life-course SEPs had an OR of 2.27 [95\% Cl: I.7I, 2.98] for heightened inflammation compared to having the highest life-course SEPs. This was jointly mediated (63 [95\% Cl: 44, 97]\%) by financial hardship and lifestyle factors.

Our study supports a cumulative effect of life-course SEPs on adult heightened systemic inflammation along the pathway paternal occupational position -> education -> adult occupational position. Financial hardship and lifestyle factors in adulthood mediate half of that effect.

KEYWORDS: childhood/adulthood socioeconomic positions, heightened inflammation, counterfactual mediation, lifestyle factors, financial hardship. 
Disadvantaged socioeconomic conditions in childhood, such as parental socioeconomic position (SEP), are linked to increased systemic inflammatory levels in adult life (Berger et al., 2019; Liu et al.,

20 17; Pollitt et al., 2007; Tabassum et al., 2008). Various processes such as infection, adipose tissue, or chronic activation of the stress response systems may lead to heightened inflammation, that has consequences for health and survival (Li et al., 20I7). For example, stressful experiences in childhood such as abuse or cumulative socioeconomic disadvantage throughout can result in an over-solicited stress response system, which in turn contributes to heightened inflammation and eventually increases the risk of poor health in adulthood (Kivimäki and Steptoe, 2018). In this mechanistic perspective, heightened inflammation represents a potential pathophysiological mechanism underlying the development of several socially patterned diseases, including cardiovascular, metabolic and psychotic disorders (Danesh et al., 2004; Dehghan et al., 2007; Ligthart et al., 20I8).

The effect of childhood SEP on inflammatory processes, and subsequent poor health, may develop through various life-course mechanisms that are not fully understood (Liu et al., 2017). An interdisciplinary approach where models from life course epidemiology and social science are combined in a unified theoretical framework has offered a way to study those complex mechanisms (Ben-Shlomo and Kuh, 2002; Cohen et al., 2010; Kuh et al., 2003; Lynch and Smith, 2005). Based on previous investigations of the life-course socioeconomic origin of adult inflammation, three lifecourse scenarios have been described: the early life critical period model, whereby exposures experienced in the critical window of childhood (such as parental low SEP) may directly affect adult inflammatory levels by permanently modifying some biological parameters (Berens et al., 2017); the accumulation or chain of risk additive model, whereby the effect of exposures to low SEP cumulates across the life-course affecting inflammatory levels in a gradient-like manner (Camelo et al., 20I4; Gimeno et al., 2007; Ploubidis et al., 2014; Tabassum et al., 2008); and the social mobility model, whereby the direction of SEP mobility across childhood and adulthood impacts adult inflammatory responses (Castagné et al., 20I6; Na-Ek et al., 20I7). Furthermore, several multiple risk factors likely mediate socioeconomic inequalities in adult heightened inflammation. Material factors such as housing 
tenure (Clair and Hughes, 2019), financial hardship via material deprivation (Groffen et al., 2007), psychosocial stress (individual, family-related or job-related) (Eddy et al., 20I6; Sturgeon et al., 2016), lifestyle factors (Berger et al., 2019; Davillas et al., 2017), psychological distress (Cohen et al., 2010) and environmental exposures (Thompson et al., 2015), are some of the modifiable risk factors.

To our knowledge, no studies have investigated the mediating roles of those risk factors within a lifecourse framework and using counterfactual-based mediation methods. Accounting for the full mechanistic pathways of potential life-course socioeconomic aetiology of heightened inflammation, in combination with modifiable later-in-life risk factors such as financial hardship and lifestyle factors, is key to understanding and therefore mitigating socioeconomic inequalities in this outcome. In this study, we advance the existing literature by: I) elucidating path-specific mechanisms where disadvantaged SEP affects inflammatory levels in adulthood across three life periods (childhood, early and full adulthood); 2) assessing the joint contribution of unhealthy lifestyle behaviour and financial hardship in adulthood in mediating life-course socioeconomic inequalities in heightened inflammation; and 3) applying counterfactual-based mediation models, which provide unbiased estimates when mediators and/or outcome are not measured on the continous scale as in our study and in most previous studies (VanderWeele et al., 20I4).

To explore multiple causal mechanisms linking early life SEP to adult heightened inflammation, we used longitudinal data from two Swiss population studies (5, I52 participants) and applied path-specific mediation based on a counterfactual framework. We evaluated socioeconomic inequalities in adult C-reactive protein (CRP). CRP is a clinical biomarker that may indicate exposure to chronic stress, and previous studies have identified an increase in CRP with lower parental SEP (Liu et al., 2107). We also determined the mediating role of financial hardship and lifestyle factors in adulthood since they are modifiable risk factors, the target of global policies (Stringhini et al., 2017) or welfare programs (Courtin et al., 2018), and consistently associated with later-in-life poor health outcomes (Carstairs and Morris, 1990; Stringhini et al., 2017; Stringhini et al., 2018). By disentagling these complex lifecourse models and mechanisms of systemic heightened inflammation in adulthood, this work could 
125 extend into potential social investment and policy recommendations to inform interventions to 126 improve population health.

127 


\section{MATERIALS AND METHODS}

129

130

131

132

133

134

135

136

137

138

139

140

141

142

143

144

145

146

147

148

149

150

151

152

153

\section{Study Populations}

Individual-participant data from two prospective Swiss cohorts were used: SKIPOGH (Alwan et al., 2014) and CoLaus/PsyCoLaus (Firmann et al., 2008). The SKIPOGH study began in December 2009 and ended in April 20I3, and included I,I 28 participants aged between 18 and 90 years recruited in Western Switzerland. A follow-up survey on 1,033 individuals started in October 2012 and was completed in December 2016. The CoLaus/PsyCoLaus study began between 2003 and 2006 and included 6,733 participants living in Lausanne, aged between 35 and 75 years; the first follow-up survey was conducted 5.5 years afterwards and included 5,064 participants. The second follow-up assessment was conducted between 2014 and 2017 and included 4,88I participants. Both studies were approved by ethical committees (see Supplementary Material).

\section{Causal models and measures}

The proposed causal structures underlying our study are shown in the directed acyclic graphs (DAGs) displayed in Figure I. We based our causal modeling to evaluate path-specific mechanisms of socioeconomic inequalities in adulthood heightened inflammation (outcome). The first two causal models (Figure IA,B) focus on inequalities driven by socioeconomic position experienced in childhood (exposure). The total effect of exposure is broken down into a non transmitted (direct effect) and transmitted (indirect effect) portion by examined intermediate mechanisms. In DAG। (Figure IA) the indirect effect represents the joint mediated effect by adulthood SEPs (individual's highest educational attainment and occupational position), financial hardship and lifestyle factors (BMI, alcohol intake, smoking status, physical inactivity) en-bloc, and we do not posit any assumption on the causal order of the mediators. A null indirect effect in DAG would support an early critical period model (Howe et al., 20I6). In $\mathrm{DAG}_{2}$ (Figure IB), the indirect effect represents the joint mediated effects by both adulthood SEPs and we assumed i) education causes occupational position, a known temporal order, and ii) downstream risk factors of financial hardship and lifestyle factors are caused by those individual's SEPs (not displayed in DAG ). By comparing the joint mediated effects in 
$D A G_{1}$ vs $D^{\prime} G_{2}$ we can understand whether financial hardship and lifestyle behaviour in adulthood provide additional mediation compared to socioeconomic positions only. Furthermore, $\mathrm{DAG}_{2}$ enabled us to investigate the paths (via education or via occupational position only) whereby SEP in childhood may propagate to affect inflammatory levels in adulthood.

Where a substantive indirect effect in $\mathrm{DAG}_{2}$ was assessed, we investigated life-course socioeconomic positions models of inequalities in heightened inflammation by two exposures: life-course trajectories of socioeconomic position and a score of disadvantaged SEPs accumulating in the course of life. The social mobility model holds if only upward/downward trajectories have a substantive effect, while the chain of risk additive model holds if a trajectory of stable (across childhood and adulthood) disadvantaged SEPs has higher effect size than upward/downward trajectories. In themselves, these have a substantive effect (Howe et al., 20I6). In DAG 3 (Figure IC) we disantangled the direct effect of the score of accumulation of life-course SEPs on heightened inflammation, and the indirect effect through financial hardship and lifestyle factors as en-bloc mediators. We did not further evaluate path-specific effects via lifestyle factors or financial hardship as their causal structure cannot be determined unequivocally.

Childhood socioeconomic position was measured through participants self-reported occupation of their fathers when they were children. Answers were classed into four categories according to the European SocioEconomic Classification (ESEC) scheme (Rose and Harrison, 2007), as done elsewhere (Stringhini et al., 2017). We categorised occupational class into high, intermediate, low, and non-working (see Supplementary Material). Paternal occupational position is a commonly used indicator of socioeconomic position in early life (Galobardes et al., 2007) and is closely related to parental occupational position in the Swiss context until the early 1970s (see Supplementary Material).

Adulthood SEPs were measured by self-reported individual's highest level of attained education (emerging adulthood) and last known occupational position (adulthood). We categorised education into university, high school, vocational and compulsory or lower (see Supplementary Material). 
181 CoLaus/PsyCoLaus and was classed into four levels as done for father's occupational position.

182 Life-course trajectories of socioeconomic position were also addressed as an exposure. Individuals

183 were classed into five trajectories: stable high (high father's and individual's occupational position), downward (high father's and intermediate or low individual's occupational position, or intermediate father's and low individual's occupational position), upward (low father's and intermediate or high individual's occupational position, or intermediate father's and high individual's occupational position), stable intermediate (intermediate father's and individual's occupational position) and stable low (low father's and individual's occupational position). Participants not working or whose father was not working were not included in examining trajectories. Finally, a score of disadvantaged SEPs accumulating along the life-course was computed by adding up the three levels of paternal occupational position, the four levels of education and the three levels of occupational position. Score ranged from a value of one (high SEP at all life phases) to eight (low SEP at all life phases), where increasing values of the score represented an accumulating exposure to disadvantaged SEP at any of the three examined life phases (childhood, emerging adulthood and adulthood). Material) in adulthood were considered as mediators. Lifestyle factors were collected at baseline in SKIPOGH and first follow-up in CoLaus/PsyCoLaus. Self-reported smoking, alcohol consumption and measured body mass index (BMI) were categorized according to WHO standards (see

199 Supplementary Material). Leisure physical activity was measured with different questions in each cohort so we dichotomised it into sedentary and active using population specific thresholds (see Supplementary Material). Self-reported financial difficulties in meeting basic needs as food, rent or health insurance were categorized as not having / having financial hardship. They were reported at first follow-up of SKIPOGH and second follow-up of CoLaus/PsyCoLaus. (CRP) in plasma. CRP is a sensitive marker of inflammatory levels and elevated amounts of CRP have been associated with increased risk for several diseases (Ligthart et al., 2018). CRP was measured 
through standard immunoturbidimetry in SKIPOGH, and through high-sensitivity

208 immunoturbidimetry in CoLaus/PsyCoLaus. We binarized CRP values by arbitrarily defining 209 heightened inflammatory levels as CRP>3mg/L (main analysis) or 4mg/L (sensitivity analysis).

210 Age, sex, cohort and self-identified ethnicity (white/other) were included as confounders in all 211 models.

\section{Mediation approach}

213 We fitted natural effect models, a class of marginal structural models directly parametrizing so-called direct and indirect effects (and more generally, path-specific effects) expressed on their natural scale (Lange et al., 20I2). Under certain identifying conditions related to confounding (Steen et al., 20l7) (see Supplementary Material), such models have practical advantages of enabling simultaneous estimation of natural direct and indirect effects, analysis of dichotomous outcomes (Lange et al., 2012), estimation of joint indirect effects (e.g. effect of exposure on outcome mediated simultaneously by a bloc of mediators) and fine-grained decompositions (path-specific indirect effects) (Steen et al., 2017). Contrary to linear path analysis (Wright, 1934; MacKinnon and Dwyer, 1993), marginal structural models allow estimation under a more general class of models including those with mediators and/or outcome measured on a non-continuous scale (as in our study) and those with an interaction between exposure and mediators (Robins et al., 2000; Vansteelandt et al., 20I2; VanderWeele et al., 20l4).

For $\mathrm{DAG}_{1}$ and $\mathrm{DAG}_{3}$ only direct and joint indirect effects were estimated, as their identification is not dependent on the true causal order of the mediators (VanderWeele and Vansteelandt, 20I4). For $\mathrm{DAG}_{2}$ (see Figure B) joint indirect effect into two path-specific indirect effects (Steen et al., 2017) were further broken down: I) the effect mediated through highest attained education ( $S \rightarrow>M_{1} \rightarrow>M_{2} \rightarrow Y$ and $S \rightarrow>M_{1} \rightarrow Y$ in Figure $\mathrm{B}$, that we denote as $\left.\left.S \rightarrow>M_{1} Y\right) ; 2\right)$ the effect mediated through individual's occupational position $\left(S->M_{2} \rightarrow Y\right)$ and not through education.

All the aforementioned joint and path-specific effects matched parameters of natural effects models. 
2017; Vansteelandt et al., 20I2) (see Supplementary Material). The proportion mediated (PM) by a bloc of mediators or through a path was derived by the ratio of the logarithms of the corresponding natural indirect effect and the total effect odds ratios (ORs).

Estimated parameters of natural effects models appear to have a causal interpretation only when all identifying conditions are satisfied (Glymour and Hamad, 2018, VanderWeele et al., 20I4).

\section{Design of the study}

Adult occupational position and lifestyle behaviour was assessed at baseline for SKIPOGH and first follow-up for CoLaus/PsyCoLaus, while C-reactive protein and financial difficulties were assessed at follow-up for SKIPOGH and second follow-up for CoLaus/PsyCoLaus. This resulted in an average of 4.8 years of gap between the assessments of lifestyle factors and C-reactive protein. Between study visits - baseline and follow-up in SKIPOGH, first follow-up and second follow-up in CoLaus/PsyColaus - a total of 269 participants were lost (4.3\%). Only participants attending both visits were included in the analysis.

\section{Statistical analyses}

Analyses were run on pooled data of the two cohorts. For 69 individuals participating in both studies, we only retained the SKIPOGH data collection. We excluded individuals with unknown ethnicity $(\mathrm{N}=2$ in CoLaus/PsyCoLaus) and missing CRP $(\mathrm{N}=12$ (I.2\%) in SKIPOGH, N=679 (I4.1\%) in CoLaus/PsyCoLaus). A total of 5, I52 participants were included in the analyses.

Father's occupational position, highest attained education and score of life-course disadvantaged SEPs were modelled as ordered variables, hypothesizing a linear effect on the outcome.

We imputed missing data (all variables but age, gender, ethnicity, cohort and CRP) through multivariate imputation by chained equations and by hypothesizing missingness at random (20 imputed data sets). Individuals with non-working fathers were excluded from each imputed data set. Confidence intervals (95\%) were estimated through percentiles from I,000 bootstrap draws (with replacement). 
258 We performed sensitivity analyses for residual confounding, model specification and effects 259 modification (see Supplementary Material).

260

261

262 


\section{RESULTS}

\section{Characteristics of the population}

Summary statistics at each level of father's occupational position are reported in Table I. Participants with low paternal occupational position were older, had lower educational attainment and occupational position, were more likely to experience financial hardship, to have higher BMI, to be sedentary, to have high alcohol intake, and to have heightened inflammation than individuals with high paternal occupational position.

\section{Mechanisms of childhood SEP inequalities}

Individuals with low father's occupational position (potentially counter to fact) had an OR of I.5I [95\% confidence interval $(\mathrm{Cl}): 1.25,1.84]$ for heightened inflammation in adulthood compared to having (potentially counter to fact) high father's occupational position (Table 2). Socioeconomic positions, financial hardship, and lifestyle factors in adult life (see Figure A) jointly mediated 59 [95\% Cl: 34, 93]\% of this effect. When only SEPs in adult life were considered as mediators (see Figure B), they jointly mediated 33 [95\% Cl: 14, 69]\%, the most important pathway being through education since path-specific mediation via occupational position only mediated $3[95 \% \mathrm{Cl}:-4,13] \%$ of the total effect.

\section{Mechanisms of life-course SEP inequalities}

All life-course trajectories of socioeconomic position resulted in an increase of odds for heightened inflammation in adulthood compared to a trajectory of high SEP across the life-course (Table 3). The odds were the highest for individuals with a consistently low trajectory from childhood to adulthood, and of similar size for the remaining other trajectories (intermediate to intermediate, downward, and upward). The analysis of the accumulation score revealed that one-unit increment of disadvantaged SEP at any life stage increased OR of I.I2 [95\% Cl: I.08, I.17] (not reported in Table 3). In particular, this resulted in an OR of 2.27 [95\% Cl: I.7I, 2.98] for heightened inflammation in adulthood for individuals with lowest life-course SEPs (low paternal occupational position, compulsory education and low occupational position potentially counter to fact) compared to having highest life-course 
289 SEPs (high paternal occupation, university education and high occupational position potentially 290 counter to fact) (see Table 3). Financial hardship and lifestyle factors in adult life jointly (see Figure C) 291 mediated 63 [95\% Cl: 44, 97]\% of this effect.

292 Sensitivity analyses

293 Results were consistent with those reported in main analyses, and with a life-course SEPs effect 294 modification by sex (see Supplementary Material). 


\section{DISCUSSION}

297 Results indicated that individuals with a low paternal occupational position when they were children

298 had higher odds of heightened inflammation in adulthood compared to their more advantaged 299 counterparts. Socioeconomic positions, financial hardship and lifestyle factors in adult life jointly

300

301

302

303

304

305

306

307

308 mediated about $60 \%$ of that effect, while educational attainment alone mediated about $30 \%$. Overall, our findings supported an accumulating effect of disadvantaged socioeconomic positions along the life-course on adult life heightened inflammation. About half of the effects of socioeconomic exposures on heightened inflammation were not mediated by the examined risk factors.

Socioeconomic inequalities by paternal occupational position are in line with results reported from a recent meta-analysis of five studies in four countries (Liu et al., 2017). The greater inequalities observed in our study (OR $=\mathrm{I} .5 \mathrm{I}$ vs $\mathrm{I} .23)$ may be explained by cross-countries variations (one of the studies run in New Zealand (Danese et al., 2009) reported an even higher odds ratio of I.96), and/or a different operationalization of the exposure (one of the studies run in the USA using parental education (Shanahan et al., 2014) reported an odds ratio of I.I5).

The proportion of the effect of father's occupational position on heightened inflammation mediated by the examined risk factors are consistent with results reported from a recent multi-cohort study $(\mathrm{N}=23,008)$ (Berger et al., 2019), although CRP was modelled as a continuous variable, and mediation was assessed through the adjustment-based method. In the study by Berger et al. (2019), lifestyle factors attenuated the association of paternal occupational position to inflammatory levels of about $58 \%$.

In our study, the marginal extra mediation accounted by adding adulthood lifestyle factors and financial hardship to socioeconomic positions is substantive (59\% vs $33 \%)$. This means that the paternal occupational position -> adult financial hardship and lifestyle factors $->$ heightened inflammation path is not entirely captured by the paternal occupational position $->$ adult socioeconomic positions -> heightened inflammation path. Other unmeasured dimensions of adulthood socioeconomic position such as assets or neighbour disadvantage may explain this marginal 
additional mediation. For example, one investigation from the Health and Retirement Study reported that the association of paternal education with obesity in adulthood was partly explained by socioeconomic position in adulthood - i.e. education, income and wealth - and fully explained when further accounting for neighbourhood disadvantage (Pavela, 2017). Alternatively, unexamined adverse childhood experiences (ACE) such as physical neglect and domestic conflicts, or other early life factors such as exposure to environmental toxics or poor nutrition during development might play a mediating role. For example, a study from the 1958 British birth cohort reported that ACE were associated to increased mid-life CRP levels and that lifestyle factors explained part of that association independently from adulthood socioeconomic positions (Chen and Lacey, 20I8).

The finding of the effect of different life-course SEP stages on heightened inflammation in adulthood supports a chain of risk additive model as a mechanism operating in our observed population, in agreement with other studies (Camelo et al., 2014; Liu et al., 2017; Tabassum et al., 2008). Given the substantive indirect effect of adult SEPs, we did not find evidence for childhood SEP to be the only (critical) determinant of inflammation in adulthood, in agreement with the former body of literature (Liu et al., 2017). Furthermore, our findings did not support a social mobility model. Overall, our results support neither the timing nor the change but the duration of exposure to low SEP across the life-course contributes to heightened CRP levels in our population.

This is one of the first studies to investigate the mediating role of financial hardship and lifestyle factors in adult life taken together with life-course SEPs. Financial hardship and lifestyle factors in adult life mediated about $60 \%$ of that effect, supporting their important mechanistic role downstream disadvantaged life-course SEPs. The remaining unexplained socioeconomic inequalities (or estimated natural direct effects) prompt for complementary, not mutually exclusive explanations. Firstly, biological embedding of those disadvantaged conditions, in particular early in life, could permanently modify some biological parameters and so inflammatory pathways throughout the life-course (Berens et al., 2017; Lupien et al., 2009). In this scenario, the critical period model could hold. Secondly, other pathways not grasped by the examined mediators may as well operate to link early/life-course SEPs and heightened inflammation in adulthood. For example, the whole impact of environmental 
factors or job-related psychosocial stress was not examined here (Eddy et al., 2016; Esposito and Giugliano, 2006; Thompson et al., 2015), although part of the effect of these factors may have been

351

352

taken into account by the assessed adulthood mediators. Finally, potential miss-classifications in exposure and mediators may have led to biased estimates of direct and indirect effects (VanderWeele et al., 20I2).

We used a marker of inflammation measured at one time point only, so limiting the internal consistency of results. Moreover, we focused on one biomarker of systemic inflammation, potentially missing aspects of inflammatory processes not entirely captured by CRP (Castagné et al., 2016; Davillas et al., 2017). Findings based on causal models $\mathrm{DAG}_{2}$ and $\mathrm{DAG}_{3}$ rely on the assumption the lifestyle behaviours are downstream adult SEP, which may have been violated in some individuals.

Residual confounding due to either a varying time interval between assessment of exposures, mediators and outcome or not included confounders may still be present and have biased our estimates. Although we carefully included several confounding factors and ran sensitivity analyses, we acknowledge that a mediation model based on nested counterfactuals rests on strong assumptions about confounding (Robins and Greenland, 1992; VanderWeele and Vansteelandt, 20I4; Vansteelandt and Daniel, 2017). Triangulation of evidence from different studies and causal inference methods are needed to strengthen our findings based on the inferred estimates (Vandenbrouke et al., 2016).

Compared to mediation analyses based on linear path analysis, our approach had the key strength of relying upon a counterfactual framework for mediation estimation even when mediators and/or outcomes were categorical and there was an interaction between exposure and mediators (Robins and Greenland, 1992; VanderWeele et al., 2014). Additional advantages of our study are the inclusion of multiple measures of socioeconomic and lifestyle factors, the life-course perspective and the pathspecific estimations. Moreover, our estimated joint indirect effects can be seen as a particular case of randomized intervention analogues, whereby the socioeconomic exposure is left unchanged and the mediator's distribution is manipulated as to be equalized between and among exposure levels (Vansteelandt and Daniel, 2017). Under this conceptualization, our study suggests that interventions 
375 to reduce socioeconomic inequalities in heightened inflammation could be performed by addressing

376 financial distress and unhealthy lifestyle among the socially disadvantaged groups of society.

\section{CONCLUSIONS}

380 Our study offers two main findings: i) the accumulation of disadvantaged socioeconomic positions

381 along the life-course pathway paternal occupational position -> education -> adult occupational 382 position is a mechanism underlying socioeconomic inequalities in adult heightened systemic 383 inflammation, and ii) financial hardship and lifestyle factors transmit about half the effect of 384 disadvantaged life-course socioeconomic exposures and some of the effect of low paternal 385 occupational position that propagates neither through education nor adult occupational position. 386 These findings can be generalized to other high-income countries with socioeconomic inequalities in 387 inflammatory levels and with distributions in the examined risk factors similar to those in 388 Switzerland. 


\section{REFERENCES}

399

400

401

402

403

404

405

406

407

408

409

410

411

412

413

414

415

416

417

418

419

420

421

422

423

Alwan H, Pruijm M, Ponte B et al. Epidemiology of masked and white-coat hypertension: the familybased SKIPOGH study. PLoS One 2014;9:e92522.

Ben-Shlomo Y, Kuh D. A life course approach to chronic disease epidemiology: conceptual models, empirical challenges and interdisciplinary perspectives. Int J Epidemiol 2002;3 I:285-93.

Berens AE, Jensen SKG, Nelson CA. Biological embedding of childhood adversity: from physiological mechanisms to clinical implications. BMC Med 2017;15:135.

Berger E, Castagné R, Chadeau-Hyam M et al. Multi-cohort study identifies social determinants of systemic inflammation over the life course. Nat Commun 2019;10:773.

Camelo LV, Giatti L, Neves JA et al. Life course socioeconomic position and C-reactive protein: mediating role of health-risk behaviors and metabolic alterations. The Brazilian Longitudinal Study of Adult Health (ELSA-Brasil). PLoS One 20I4;9:el08426.

Carstairs V, Morris R. Deprivation and health in Scotland. Health Bull (Edinb) 1990;48:162-75.

Castagné R, Delpierre C, Kelly-Irving $M$ et al. A life course approach to explore the biological embedding of socioeconomic position and social mobility through circulating inflammatory markers. Sci Rep 2016;6:25170.

Chen M, Lacey RE. Adverse childhood experiences and adult inflammation: findings from the 1958 British birth cohort. Brain Behav Immun 2018;69:582-90 
Clair A, Hughes A. Housing and health: new evidence using biomarker data. J Epidemiol Community Health 2019;73:256-62.

Cohen S, Janicki-Deverts D, Chen E, Matthews KA. Childhood socioeconomic status and adult health. Ann N Y Acad Sci 20 I0; I I 86:37-55.

Courtin E, Muennig P, Verma $\mathrm{N}$ et al. Conditional cash transfers and health of low-income families in the US: Evaluating the family rewards experiment. Health Aff (Millwood) 20I8;37:438-46.

Danese A, Moffitt TE, Harrington $\mathrm{H}$ et al. Adverse childhood experiences and adult risk factors for age-related disease. Arch Pediatr Adolesc Med 2009; I 63: I I 35-43.

Danesh J, Wheeler JG, Hirschfield GM et al. C-reactive protein and other circulating markers of inflammation in the prediction of coronary heart disease. N Engl J Med 2004;350: I 387-97.

Davillas A, Benzeval M, Kumari M. Socio-economic inequalities in C-reactive protein and fibrinogen across the adult age span: Findings from Understanding Society. Sci Rep 2017;7:264I.

Dehghan A, Kardys I, de Maat MP et al. Genetic variation, C-reactive protein levels, and incidence of diabetes. Diabetes 2007;56: 872-8.

Eddy P, Heckenberg R, Wertheim EH, Kent S, Wright BJ. A systematic review and meta-analysis of the effort-reward imbalance model of workplace stress with indicators of immune function. J Psychosom Res 2016;91:1-8.

Esposito K, Giugliano D. Diet and inflammation: a link to metabolic and cardiovascular diseases. Eur Heart J 2006;27:15-20. 
452 Firmann M, Mayor V, Vidal PM et al. The CoLaus study: a population-based study to investigate the

453

454

455

456

457

458

459

460

461

462

463

464

465

466

467

468

469

470

471

472

473

474

475

epidemiology and genetic determinants of cardiovascular risk factors and metabolic syndrome. BMC Cardiovasc Disord 2008;8:6.

Galobardes B, Lynch J, Davey Smith G. Measuring socioeconomic position in health research. Br Med Bull 2007;8 I-82:2 I-37.

Gimeno D, Ferrie JE, Elovainio $M$ et al. When do social inequalities in C-reactive protein start? A life course perspective from conception to adulthood in the Cardiovascular Risk in Young Finns Study. Int J Epidemiol 2007;37:290-8.

Glymour MM, Hamad R. Causal thinking as critical tool for eliminating social inequalities in health. Am J Public Health 2018; 1 08:623

Groffen DAI, Bosma H, van den Akker M, Kempen GIJM, van Eijk JTM. Material deprivation and health-related dysfunction in older Dutch people: findings from the SMILE study. Eur J Public Health $2007 ;$ | 8:258-63.

Howe LD, Smith AD, Macdonald-Wallis C et al. Relationship between mediation analysis and the structured life course approach. Int J Epidem 2016;45:1280-94.

Kivimäki M, Steptoe A. Effects of stress on the development and progression of cardiovascular disease. Nat Rev Cardiol 20 I 8; I 5:2 I 5-229. 
Kuh D, Ben-Shlomo Y, Lynch J et al. Life course epidemiology. J Epidemiol Community Health 2003;57:778-83.

478

Lange TS, Vansteelandt S, Bekaert M. A simple approach for estimating natural direct and indirect 480 effects. Am J Epidemiol 2012;176:190-5.

481

Li Y, Zhong X, Cheng G, et al. Hs-CRP and all-cause, cardiovascular, and cancer mortality risk: a meta-analysis. Atherosclerosis 2017;259:75-82.

484

Ligthart S, Vaez A, Võsa U et al. Genome Analyses of $>200,000$ Individuals identify 58 loci for chronic inflammation and highlight pathways that link inflammation and complex disorders. Am J Hum Genet 20I8;103:69I-706.

488

Lynch J, Smith GD. A life course approach to chronic disease epidemiology. Annu Rev Public Health

490 2005;26:I-35.

491

492

Liu RS, Aiello AE, Mensah FK et al. Socioeconomic status in childhood and C reactive protein in adulthood: a systematic review and meta-analysis. J Epidemiol Community Health 20I7;7 I:8 I7-26.

494

495

Lupien SJ, McEwen BS, Gunnar MR, Heim C. Effects of stress throughout the lifespan on the brain, 496 behaviour and cognition. Nat Rev Neurosci 2009; 10:434-45.

497

498

MacKinnon DP, Dwyer JH. Estimating mediated effects in prevention studies, Eval Rev 1993; 17:144-

499 58.

500

$501 \mathrm{Na}-E k \mathrm{~N}$, Demakakos P. Social mobility and inflammatory and metabolic markers at older ages: the 502 English Longitudinal Study of Ageing. J Epidemiol Community Health 20 I 7;7 I:253-60. 
504 Pavela G. Childhood socioeconomic status independently associated with adult BMI after accounting 505 for adult and neighbourhood socioeconomic status? PLoS One 20 I7; I 2:e0 I6848I.

506

507 Ploubidis GB, Benova L, Grundy E, Laydin D, DeStavola B. Lifelong socio economic position and 508 biomarkers of later life health: Testing the contribution of competing hypotheses. Soc Sci Med $509 \quad 2014 ;$ I I 9:258-265.

510

Pollitt RA, Kaufman JS, Rose KM, Diez-Roux AV, Zeng D, Heiss G. Early-life and adult socioeconomic status and inflammatory risk markers in adulthood. Eur J Epidemiol 2007;22: 55-66.

Robins JM, Greenland S. Identifiability and exchangeability for direct and indirect effects. Epidemiology 1992;3: 143-55.

Robins JM, Hernan MA, Brumback B. Marginal structural models and causal inference in epidemiology. Epidemiology 2000; I I:550-560.

Rose D, Harrison E. The European socio-economic classification: A new social class schema for comparative European research. European Societies 2007;9:459-90.

522

Shanahan L, Freeman J, Bauldry S. Is very high C-reactive protein in young adults associated with indicators of chronic disease risk? Psychoneuroendocrinology 20।4;40:76-85.

525

Steen J, Loeys T, Moerkerke B, Vansteelandt S. Flexible mediation analysis with multiple mediators. 

determinants of premature mortality: a multicohort study and meta-analysis of 1.7 million men and women. Lancet 2017;389:1229-37.

532

Stringhini S, Carmeli C, Jokela M, et al. Socioeconomic status, non-communicable disease risk factors, and walking speed in older adults: multi-cohort population based study. BMJ 2018;360:k1046.

Sturgeon JA, Arewasikporn A, Okun MA, Davis MC, Ong AD, Zautra AJ. The psychosocial context of financial stress: Implication for inflammation and psychological health. Psychosom Med 2016;78:13443.

Tabassum F, Kumari M, Rumley A, Lowe G, Power C, Strachan DP. Effects of socioeconomic position on inflammatory and hemostatic markers: a life-course analysis in the 1958 British birth cohort. Am J Epidemiol 2008; 167:1332-4I.

Thompson PA, Khatami M, Baglole CJ et al. Environmental immune disruptors, inflammation and cancer risk. Carcinogenesis 20I5;36:S232-53.

Vandenbrouke JP, Broadbent A, Pearce N. Causality and causal inference in epidemiology: the need for a pluralistic approach. Int J Epidemiol 2016;45:1776-1786

VanderWeele TJ, Valeri L, Ogburn EL. The role of measurement error and misclassification in mediation analysis. Epidemiology 20| 2;23:56 |-4. induced mediator-outcome confounder. Epidemiology 2014;25:300-6. 
$557 \quad 2014 ; 2: 95-115$.

558

559 Vansteelandt S, Bekaert M, Lange T. Imputation strategies for the estimation of natural direct and 560 indirect effects. Epidemiol Methods 20 I2; I: I31-58.

561

562

Vansteelandt S, Daniel RM. Interventional effects for mediation analysis with multiple mediators.

563

Epidemiology 20I7;28:258-65.

564

565

Wright S. The method of path coefficients. Ann Math Statist 1934;5:16I-2I5.

566

567

568

569

570

571

572

573

574

575

576

577

578

579 
581 FIGURE I

A

B

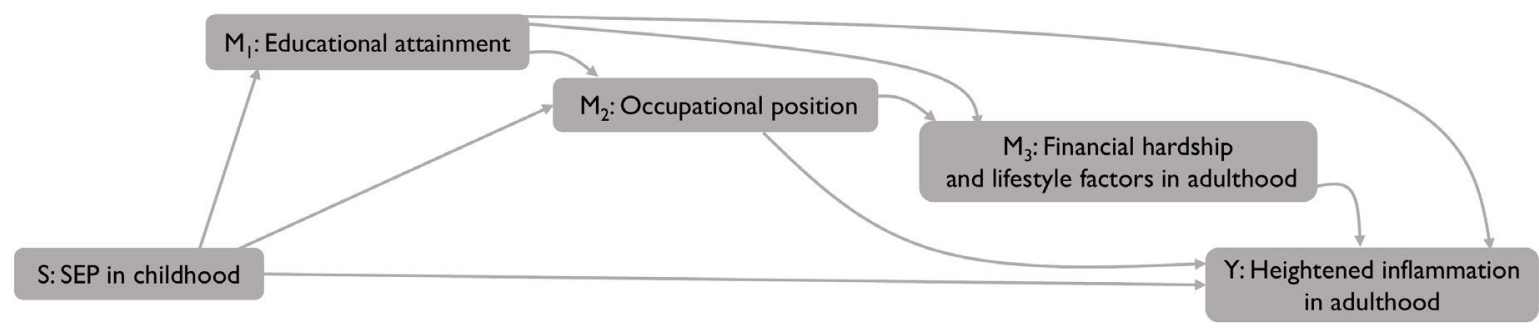

C

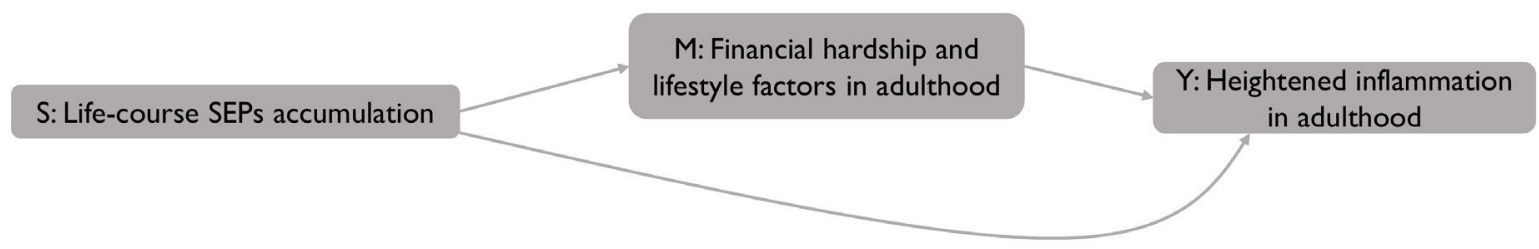

583 Causal models posited in the study. Confounders (sex, ethnicity, age and cohort) are not drawn for the sake of simplicity. A) DAG, of the effect of socioeconomic position (SEP) in childhood (father's occupational position or S) on adulthood heightened inflammation (Y). SEPs (individual's educational attainment and occupational position), financial hardship, lifestyle factors (BMI, alcohol intake, smoking status, and physical

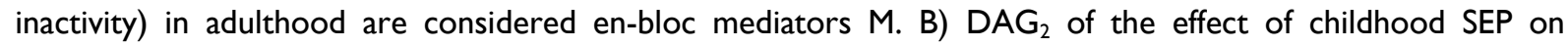
adulthood heightened inflammation through individual's educational attainment $\left(M_{1}\right)$, occupational position $\left(M_{2}\right)$, and lifestyle behaviours and financial hardship in adulthood $\left(M_{3}\right)$.

C) $\mathrm{DAG}_{3}$ of the effect of accumulation of lifecourse SEPs (paternal occupational position, individual's educational attainment and occupational position or S) on adulthood heightened inflammation. Financial hardship and lifestyle factors in adulthood are considered enbloc mediators. 
597 TABLES

598 Table I. Characteristics of the pooled populations according to levels of childhood socioeconomic exposure $599(\mathrm{~N}=4,707$ after removing participants whose father's occupational position is unknown $(\mathrm{N}=404)$ and whose 600 father was non-working $(\mathrm{N}=46))$. Continuous characteristics are summarized through their mean and 601 lower/upper quartiles. Categorical characteristics are summarized through their absolute and relative (\%) 602 prevalence. P values (rightmost column) for differences between levels of father's occupational position are 603 obtained from a chi-squared test for categorical characteristics ( $\chi^{2}$ is the chi-squared statistics) and a linear 604 model for continuous ones ( $T$ stands for t-statistics).

605

\begin{tabular}{|c|c|c|c|c|}
\hline $\begin{array}{c}\text { Father's } \\
\text { occupational position / } \\
\text { Characteristics }\end{array}$ & Low & Intermediate & High & $P$ value \\
\hline $\mathrm{N}$ & $|34|(29 \%)$ & 1990 (42\%) & $1376(29 \%)$ & - \\
\hline Age [years] & $6 \mid(52,70)$ & $60(52,7 I)$ & $59(5 I, 68)$ & $0.0002(T=3.7)$ \\
\hline $\begin{array}{c}\text { Sex } \\
\text { [woman/man] }\end{array}$ & $\begin{array}{l}714(53 \%) \\
627(47 \%)\end{array}$ & $\begin{array}{l}\text { IIOI (55\%) } \\
889 \text { (45\%) }\end{array}$ & $\begin{array}{l}737 \text { (54\%) } \\
639 \text { (46\%) }\end{array}$ & $0.42\left(\chi^{2}=1.7\right)$ \\
\hline $\begin{array}{c}\text { Ethnicity } \\
\text { [white/other] }\end{array}$ & $\begin{array}{c}1270 \text { (95\%) } \\
7 \mid(5 \%)\end{array}$ & $\begin{array}{c}1882(95 \%) \\
108(5 \%)\end{array}$ & $\begin{array}{c}1273(92 \%) \\
103(8 \%)\end{array}$ & $0.02\left(\chi^{2}=7.7\right)$ \\
\hline $\begin{array}{l}\text { Highest attained education } \\
\text { [compulsory/vocational/ } \\
\text { high-school/university] }\end{array}$ & $\begin{array}{l}264(20 \%) \\
581(44 \%) \\
186(14 \%) \\
295(22 \%)\end{array}$ & $\begin{array}{l}365(19 \%) \\
819(42 \%) \\
285(15 \%) \\
488(25 \%)\end{array}$ & $\begin{array}{c}43(3 \%) \\
242(18 \%) \\
256(19 \%) \\
819(60 \%)\end{array}$ & $<2^{*} * 10^{-16}\left(\chi^{2}=722.5\right)$ \\
\hline $\begin{array}{l}\text { Occupational position } \\
\text { [low/intermediate/high/ } \\
\text { not working] }\end{array}$ & $\begin{array}{c}393(30 \%) \\
590(44 \%) \\
116(9 \%) \\
230(17 \%)\end{array}$ & $\begin{array}{l}484(25 \%) \\
861(44 \%) \\
209(11 \%) \\
385(20 \%)\end{array}$ & $\begin{array}{l}136(10 \%) \\
645(48 \%) \\
385(28 \%) \\
186(14 \%)\end{array}$ & $<2 * 10^{-16}\left(\chi^{2}=365.7\right)$ \\
\hline Financial difficulties & $208(16 \%)$ & $292(15 \%)$ & $156(12 \%)$ & $0.002\left(\chi^{2}=12.5\right)$ \\
\hline
\end{tabular}




\begin{tabular}{|c|c|c|c|c|}
\hline [yes/no] & 1076 (84\%) & 1613 (85\%) & II 78 (88\%) & \\
\hline $\begin{array}{c}\text { Heightened inflammation } \\
\text { [yes/no] }\end{array}$ & $\begin{array}{l}276(21 \%) \\
1065(79 \%)\end{array}$ & $\begin{array}{l}355(18 \%) \\
1635(82 \%)\end{array}$ & $\begin{array}{l}196(14 \%) \\
1180(86 \%)\end{array}$ & $7.5^{*} * 10^{-5}\left(\chi^{2}=19.0\right)$ \\
\hline $\begin{array}{c}\text { Smoking status } \\
\text { [current/former/never } \\
\text { smoker] }\end{array}$ & $\begin{array}{l}27 \mathrm{I}(22 \%) \\
439(35 \%) \\
529(43 \%)\end{array}$ & $\begin{array}{l}386(21 \%) \\
659(36 \%) \\
787(43 \%)\end{array}$ & $\begin{array}{l}264(21 \%) \\
489(38 \%) \\
532(41 \%)\end{array}$ & $0.67\left(\chi^{2}=2.4\right)$ \\
\hline $\begin{array}{c}\text { Body mass index } \\
\text { [obese/overweight/normal } \\
\text { /underweight] }\end{array}$ & $\begin{array}{c}220(18 \%) \\
525(42 \%) \\
482(39 \%) \\
12(1 \%)\end{array}$ & $\begin{array}{c}304(16 \%) \\
699(36 \%) \\
798(46 \%) \\
32(2 \%)\end{array}$ & $\begin{array}{c}\text { I36 (I I\%) } \\
434(34 \%) \\
686(53 \%) \\
29(2 \%)\end{array}$ & $3.1 * 10^{-14}\left(\chi^{2}=75.4\right)$ \\
\hline $\begin{array}{c}\text { Alcohol intake } \\
\text { [high/moderate/abstainer] }\end{array}$ & $\begin{array}{l}113(9.1 \%) \\
799(64.5 \%) \\
326(26.3 \%)\end{array}$ & $\begin{array}{c}140(7.6 \%) \\
1144(62.2 \%) \\
555(30.2 \%)\end{array}$ & $\begin{array}{l}102(8 \%) \\
896(70 \%) \\
288(22 \%)\end{array}$ & $3.2 * 10^{-5}\left(\chi^{2}=26.0\right)$ \\
\hline $\begin{array}{l}\text { Physical activity } \\
\text { [sedentary/active] }\end{array}$ & $\begin{array}{l}624(56.4 \%) \\
482(43.6 \%)\end{array}$ & $\begin{array}{l}867(52.9 \%) \\
772(47.1 \%)\end{array}$ & $\begin{array}{l}540(47 \%) \\
615(53 \%)\end{array}$ & $1.7^{*} 10^{-5}\left(\chi^{2}=21.9\right)$ \\
\hline $\begin{array}{c}\text { Prevalent diabetes } \\
\text { [yes } / \mathrm{no}]\end{array}$ & $\begin{array}{l}116(9.3 \%) \\
1129(90.7 \%)\end{array}$ & $\begin{array}{c}139(7.5 \%) \\
1708(92.5 \%)\end{array}$ & $\begin{array}{c}90(7 \%) \\
1200(93 \%)\end{array}$ & $0.07\left(\chi^{2}=5.3\right)$ \\
\hline $\begin{array}{l}\text { History of stroke or } \\
\text { coronary heart diseases } \\
\text { [yes/no] }\end{array}$ & $\begin{array}{c}7 \mid(6 \%) \\
\mid 173(94 \%)\end{array}$ & $\begin{array}{c}114(6 \%) \\
1729(94 \%)\end{array}$ & $\begin{array}{c}58(5 \%) \\
1228(95 \%)\end{array}$ & $0.13\left(\chi^{2}=4.1\right)$ \\
\hline $\begin{array}{c}\text { Co-morbidities } \\
\text { [yes/no] }\end{array}$ & $\begin{array}{l}172(13 \%) \\
1169(87 \%)\end{array}$ & $\begin{array}{l}240(12 \%) \\
1750(88 \%)\end{array}$ & $\begin{array}{r}140(10 \%) \\
1236(90 \%)\end{array}$ & $0.08\left(\chi^{2}=5.0\right)$ \\
\hline
\end{tabular}

606

607

608

609

610

611 

socioeconomic position on heightened inflammation in adulthood, estimated through the natural effect model. PM stands for proportion mediated (ratio of the indirect and total effect OR logarithm). The average population size across imputation and bootstrap draws was $\mathrm{N}=5,105$.

Parameter estimates

OR $[95 \% \mathrm{CI}]$

\begin{tabular}{|c|c|}
\hline Total effect of father's occupational position & $1.51[1.25,1.84]$ \\
\hline Direct effect $D A G_{\mid}$ & $\mathrm{I} .18[0.97, \mathrm{I} .46]$ \\
\hline Joint indirect effect DAG & I.27 [I.17, I.39]; PM = $59[34,93] \%$ \\
\hline Direct effect $\mathrm{DAG}_{2}$ & $1.32[1.07,1.63]$ \\
\hline Joint indirect effect $\mathrm{DAG}_{2}$ & I.I5 [I.07, I.23]; PM = $33[14,69] \%$ \\
\hline $\begin{array}{l}\text { Mediation through educational attainment } \\
S->M_{1} Y\end{array}$ & $P M=30[11,64] \%$ \\
\hline $\begin{array}{l}\text { Partial mediation through occupational position } \\
S->M_{2}->Y\end{array}$ & $P M=3[-4,13] \%$ \\
\hline
\end{tabular}

616

617

618

619

620

621

622

623

624 
Table 3. Odds ratio $(O R)$ and $95 \%$ confidence intervals $(\mathrm{Cl})$ for associations of life-course occupational positions trajectories and effects of highest (vs lowest) score of accumulation of life-course disadvantaged SEPs on heightened inflammation in adulthood. The trajectories' ORs were estimated compared to individuals with high father's occupational position and high individual occupational position. Highest score was defined by having low father's occupational position, compulsory education, and low occupational position, while lowest score by having high father's occupational position, university education and high occupational position. PM stands for proportion mediated (ratio of the indirect and total effect OR logarithm). The average total population size across imputation and bootstrap draws was $N=4,170$, of which $N=406$ were stable high, $N=449$ stable low, $\mathrm{N}=937$ stable intermediate, $\mathrm{N}=973$ upward, and $\mathrm{N}=1,405$ downward.

\section{Parameter estimates}

\begin{tabular}{l|l} 
Stable low life-course trajectory & $2.79[1.98,4.28]$ \\
\hline Stable intermediate life-course trajectory & $\mathrm{I.73}[1.22,2.57]$ \\
\hline Upward life-course trajectory & $\mathrm{I} .83[1.32,2.67]$ \\
\hline Downward life-course trajectory & $\mathrm{I} .92[1.39,2.85]$ \\
\hline
\end{tabular}

\begin{tabular}{l|l} 
Total effect of accumulation score & $2.27[1.71,2.98]$ \\
\hline Direct effect DAG & \\
\hline Joint indirect effect DAG & $1.35[1.02,1.80]$ \\
\hline
\end{tabular}

634 


\section{Study Populations}

Individual-participant data from two prospective Swiss cohort studies were used: the Swiss Kidney Project on Genes in Hypertension (SKIPOGH) and the COhorte LAUSannoise (CoLaus/PsyCoLaus).

SKIPOGH. The SKIPOGH study was a multi-centre population-based study initiated in December 2009 to explore the genetic and environmental determinants of blood pressure (Alwan et al., 2014; Ponte et al., 2014). Study participants were recruited in the cantons of Bern and Geneva and in the city of Lausanne, Switzerland. Recruitment ended in April 2013 for the baseline assessment and included I, I 28 participants aged between 18 and 90 . A follow-up survey on I,033 individuals started in October 2012 and was completed in December 2016. The SKIPOGH study was approved by the ethical committees of Lausanne University Hospital, Geneva University Hospital and the University Hospital of Bern.

CoLaus/PsyCoLaus. The CoLaus/PsyCoLaus study is an ongoing prospective cohort study assessing the clinical, biological and genetic determinants of cardiovascular disease in the city of Lausanne, Switzerland (Firmann et al., 2008). The initial survey was conducted between 2003 and 2006 and included 6,733 participants aged between 35 and 75; the first follow-up survey was conducted 5.5 years afterwards and included 5,064 participants. The second follow-up assessment was carried out between 2014 and 2017 and included 4,88I participants. The CoLaus/PsyCoLaus study was approved by the ethical committee of the University of Lausanne.

\section{Measures}

Childhood socioeconomic position. In the follow-up of the SKIPOGH study and the second followup of the CoLaus/PsyCoLaus study, participants were asked to report their father's profession when they were children, and this was used as a proxy of socioeconomic position in early life. Answers were mapped into four categories according to the European SocioEconomic Classification (ESEC) scheme. We categorised occupational class into high (higher professionals and managers, higher clerical, services, and sales workers (European socioeconomic class I-3)), intermediate (small employers and self-employed, farmers, lower supervisors and technicians, class 4-6), or low (lower clerical, services, and sales workers, skilled workers, semi-skilled and unskilled workers, class 7-9)] (Rose and Harrison, 2007). Finally, fathers who were reported to be retired or not working were classed as not working.

Paternal occupational position is a commonly used indicator of socioeconomic positions in early life (Galobardes et al., 2007) and is closely related to parental occupational position in the Swiss context until the early 1970s. Indeed, according to census data (Swiss Federal Statistical Office), in 1970 the percentage of non-working women living in a household with children (0-13 years) was $73 \%$, and the percentage of those working full time was $8 \%$. Participants in our study were born on average in 1955, with $90 \%$ of participants being born by 1968 .

Emerging adulthood socioeconomic position. Self-reported highest level of attained education was used as a measure of emerging adulthood socioeconomic position. We categorised the variable into university (university degree and any superior non-university training), high school (secondary school), vocational (apprenticeship in CoLaus/PsyCoLaus and vocational training in SKIPOGH) or mandatory or lower (mandatory school in CoLaus/PsyCoLaus and mandatory school or no diploma in SKIPOGH). Information was collected at baseline for both population studies.

Adulthood socioeconomic position. Individual's last known occupational position in adulthood was considered as a proxy for adulthood socioeconomic position. Categorization into four levels was performed according to the same scheme as for father's occupational position. Non working 
individuals were either self-identified housewifes or unemployed. Information on current or past occupational position were available at baseline of SKIPOGH and first follow-up of CoLaus/PsyCoLaus. In order to minimize the missing job titles, we complemented that with information on occupational position available at baseline for CoLaus/PsyCoLaus.

Life-course trajectories of socioeconomic positions. Father's and individual occupational position were integrated to generate five life-course trajectories of socioeconomic positions. Individuals were classified into stable high (high father's and individual's occupational position), downward (high father's occupational position and intermediate or low individual's occupational position, or intermediate father's occupational position and low individual's occupational position), upward (low father's occupational position and intermediate or high individual's occupational position, or intermediate father's occupational position and high individual's occupational position), stable intermediate (intermediate father's and individual's occupational position) and stable low (low father's and individual's occupational position).

Furthermore, a score of disadvantaged socioeconomic positions accumulating along the life-course was computed. The score was operationalized by adding up the three levels of paternal occupational position (not working fathers were excluded), the four levels of education and the three levels of occupational position (not working individuals were excluded). That score ranged from I to 8 , where I stood for participants who held a high occupational position, had university education and whose father's occupational position was also high. Conversely, a value of 8 represented participants who held a low occupational position, had compulsory education and whose father's occupational position was low. Increasing values of the score represented an accumulating exposure to disadvantaged socioecomic conditions at any of the three life periods we investigated.

Financial hardship in adulthood. Financial difficulties in meeting basic needs as food, rent or health insurance were self reported at first follow-up of SKIPOGH and second follow-up of CoLaus/PsyCoLaus. Four answers were possible: i) "never happened"; ii) "not currently but this has happened before"; iii) "yes, started less than a year ago"; iv) "yes, lasting several years". We categorized them into two groups, defined as not having current financial difficulties (i or ii), or as having current financial difficulties (iii or iv).

Lifestyle factors in adulthood. Self-reported smoking was classed into current, former, and never. Alcohol consumption was measured in alcohol units weekly, and we categorised participants as abstainers ( 0 units/week), moderate drinkers (I-2I units/week for men, I-I4 units/week for women), or harmful drinkers (>2I units/week for men, >I4 units/week for women). Height and weight were measured using standard procedures; body mass index (BMI) was calculated as $\mathrm{kg} / \mathrm{m}^{2}$ and categorised as underweight $(<18.5)$, normal $(18.5$ to $<25)$, overweight $(25$ to $<30)$, or obese $(\geq 30)$. Leisure physical activity was measured with different questions in each study so we dichotomised it into sedentary and active using population specific thresholds. In SKIPOGH, those reporting to not practice sport on a regular basis were classified as sedentary, and those reporting to practice regularly sport were classified as non-sedentary or active. In CoLaus/PsyCoLaus participants expending more than $90 \%$ of daily energy expenditures in activities less intense than moderate or high-intensity (defined by expending at least four times one's basal metabolic rate) were classified as sedentary, and active otherwise (Bernstein et al., 1999). Lifestyle factors were collected at baseline in SKIPOGH and first follow-up in CoLaus/PsyCoLaus.

Systemic inflammatory levels in adulthood. Inflammatory levels were assessed through the amount of circulating C-reactive protein (CRP) in plasma at follow-up in SKIPOGH and second follow-up in COLAUS. CRP is a sensitive marker of inflammatory levels and elevated amounts of CRP have been associated with increased risk for several diseases (Emerging Risk Factors Collaboration et al., 20I0). In SKIPOGH, CRP was measured through standard immunoturbidimetry with different detection limits depending on the center, $3 \mathrm{mg} / \mathrm{L}$ being the highest. Most SKIPOGH participants $(\sim 60 \%)$ had CRP values below the detection limits. In COLAUS, CRP was measured through high-sensitivity immunoturbidimetry with a detection limit of $0.1 \mathrm{mg} / \mathrm{L}$. We binarized CRP values by arbitrarily defining heightened inflammation when CRP exceeded $3 \mathrm{mg} / \mathrm{L}$ or $4 \mathrm{mg} / \mathrm{L}$. 
Other. Age at follow-up for SKIPOGH and second follow-up for CoLaus/PsyCoLaus, sex, cohort and ethnicity. For SKIPOGH, the cohort indicator included information about the three centres. Selfreported ethnicity was dichotomized in being white or other. In SKIPOGH, no more detailed information about non-white participants was collected.

Diabetes was defined as the presence of at least one of fasting glucose concentration $\geq 7 \mathrm{mmol} / \mathrm{L}$ or self-reported medication for diabetes. History of stroke or coronary heart diseases (myocardial infarction, heart failure, percutaneous coronary intervention or coronary artery bypass graft) was self-reported. Diabetes, history of stroke and coronary heart diseases were measured at baseline in SKIPOGH and first follow-up in CoLaus/PsyCoLaus. Individuals with diabetes, history of stroke or coronary heart diseases and with a class III BMI (BMI $\geq 40)$ were dichotomized as having inflammation related co-morbidities or not.

Table SI reports prevalences and frequencies of all introduced characteristics in both population studies.

\section{Counterfactual-based mediation framework}

We adopted a counterfactual mediation framework to disentangle direct and indirect effects of the exposure(s) on the outcome, via multiple mediators. Contrary to traditional path analysis based on parametric structural equation modelling, mediation analysis based on counterfactuals rely on formal causal arguments and it allows path tracing even with binary outcomes, whereas the traditional path analysis rely on stringent parametric constraints (MacKinnon and Dwyer, 1993). In this study, marginal natural effect models, a class of marginal structural models for parametrizing and estimating so-called direct and indirect effects (and more generally, path-specific effects) expressed on their natural scale (Lange et al., 20I2) were fitted.

Let's nested counterfactuals $Y\left(s, M\left(s^{*}\right)\right)$ denote the heightened inflammation that would have been observed if exposure were set to high paternal occupational position or highest life-course SEPs (s) and mediators $M$ to the value it would have taken if exposure were set to low paternal occupational position or lowest life-course SEPs $\left(s^{*}\right)$. Denoting as $C$ the set of confounders and hypothesizing no product terms, in main analyses we posited the following natural effect model

$\operatorname{logit}\left[E\left\{Y\left(s, M\left(s^{*}\right)\right) \mid C\right\}\right]=\beta_{0}+\beta_{1} s+\beta_{2} s^{*}+\beta_{3} C$

From it, we can simultaneously estimate the natural direct effect odd ratio as

$$
\frac{\operatorname{odd} s\left\{Y\left(s, M\left(s^{*}\right)\right)=1 \mid C\right\}}{\operatorname{odd}\left\{Y\left(s^{*}, M\left(s^{*}\right)\right)=1 \mid C\right\}}=\exp \left\{\beta_{1}\left(s-s^{*}\right)\right\}
$$

and the natural indirect effect as

$\frac{\operatorname{odd}\{\{Y(s, M(s))=1 \mid C\}}{\operatorname{odd} s\left\{Y\left(s, M\left(s^{*}\right)\right)=1 \mid C\right\}}=\exp \left\{\beta_{2}\left(s-s^{*}\right)\right\}$.

Their product measures the total effect odds $\{Y(s)=|| C\} / \operatorname{odds}\left\{Y\left(s^{*}\right)=|| C\right\}$.

Under certain identifying conditions, natural effect models enable estimation of joint indirect effects (e.g. effect of exposure on outcome mediated simultaneously by a bloc of mediators) and fine-grained decompositions (path-specific indirect effects) (Steen et al., 2017a).

For $D A G_{1}$ and $D A_{3}$ we estimated only direct and joint indirect effects, as their identification was not dependent on the true causal order of the mediators (VanderWeele and Vansteelandt, 20I4). In other words, joint effects are robust to potential misspecifications of the causal order. This property was useful in our case since the interrelations between financial hardship and lifestyle factors cannot be determined unequivocally. Effects are identifiable if there are no unmeasured confounders of exposure-outcome, exposure-mediators and mediators-outcome relations. Furthermore, contrary to 
other types of path-specific effects, joint effects are identifiable under unmeasured confounding (not induced by the exposure) among the mediators (Steen et al., 20I7a). In DAG, the direct effect not accounted for by educational attainment, occupational position, financial hardship and lifestyle factors were taken as the effect on inflammation when changing individual's exposure from high to low father's occupational position while keeping the value of the mediators at the level they had if individuals were exposed to high father's occupational position. The joint indirect effect mediated by all mediators taken together $(S->M->Y$, in Figure IA) indicated the effect on heightened inflammation when altering the levels of the mediators from levels observed if exposed to high father's occupational position to levels that would have been observed at low father's occupational position while otherwise remaining exposed to high father's occupational position. We mention that joint indirect effects have an alternative interpretation, first proposed by VanderWeele and Robinson (2014) in the context of non-modifiable exposures as ethnicity (VanderWeele and Robinson, 20I4). Within this conceptualization, the natural joint indirect effect might be interpreted as a particular case of randomized intervention analogues, whereby the exposure is left unchanged and the mediator's distribution is manipulated as to equalize it between the levels of exposure (VanderWeele and Robinson, 2014; Vansteelandt and Daniel, 2017). Under the natural effect model estimation, this equivalence holds if all identifying conditions mentioned above are satisfied.

Path-specific effects in $\mathrm{DAG}_{2}$ (see Figure IB) assessment was a two-step process. First, the total effect of father's occupational position on adulthood heightened inflammation was broken down in direct and joint indirect effects. Second, we further decomposed the joint indirect effect into two path-specific indirect effects (Steen et al., 2017a): I) the effect mediated through highest attained education

$S->M_{1}->M_{2}->Y$ and $S->M_{1}->Y$ in Figure IB, that we denote as $S->M_{1} Y$ ); 2) the effect mediated directly through individual's occupational position $\left(S->M_{2}->Y\right)$ and not through education. This further decomposition requires additional identifying assumptions, namely that there is no unmeasured confounding among the pair of mediators and no confounders of the mediatoroutcome relations (either measured or unmeasured) are themselves affected by exposure.

All the aforementioned joint and path-specific effects corresponded to parameters of natural effects models and were estimated via an imputation model of the nested counterfactuals (Vansteelandt et al., 20l4). This was performed in three steps by: i) fitting logistic regression models for heightened inflammation with father's occupational position/accumulation score, the mediators and confounders as explanatory variables; ii) imputing the counterfactual heightened inflammation for each combination of unobserved (counterfactual) exposures and observed mediators levels; and iii) fitting a logistic natural effect model for imputed heightened inflammation. In all cases, we specified models for the outcome imputation to reflect the structure of the natural effects models (Vansteelandt et al., 2014). Under the assumption of an outcome imputation model correctly specified and congenial with the natural effect model (Vansteelandt et al., 2014), this estimation approach is appealing because it is parsimonious in that it requires specifying only one model even in the presence of multiple mediators. Furthermore, in empirical simulations it provided adequate estimates compared to inverse probability and doubly robust estimators (Vansteelandt et al., 2014).

In main analyses, product terms between exposure and mediators on the multiplicative scale were not included in the counterfactual imputation model based on weak evidence from likelihood ratio tests $\left(P\right.$ value $=0.42,0.55,0.48$ for $D A G_{1,2,3}$ respectively). Product terms among mediators in $D^{2} G_{2}$ were included based on likelihood ratio test $(P$ value $=0.04)$. Product terms among mediators in $D_{A G_{1,3}}$ could not be reliably estimated given their high numbers compared to the available population size, consequently they were not included in the outcome imputation model.

Analyses were performed in R 3.5.I (medflex (Steen et al., 20I7b) for joint mediations, and in house scripts for path-specific mediations). 


\section{Sensitivity analyses}

We ran sensitivity analyses to investigate the stability of analyses upon a different choice of CRP cutoff $(4 \mathrm{mg} / \mathrm{L}$ vs $3 \mathrm{mg} / \mathrm{L})$, removing participants with CRP>10 $\mathrm{mg} / \mathrm{L}$ or with co-morbidities. We removed individuals with the aforementioned high CRP values by hypothesizing that they reflected short-term immune responses due to current illness that might confound (possibly induced by life-course accumulation of disadvantaged SEPs, $\mathrm{DAG}_{3}$ ) the effect of adulthood financial hardship or lifestyle factors on heightened inflammation. The same hypothesis underlies the removal of participants with co-morbidities.

Furthermore, we estimated joint indirect effects when adding co-morbidities as an additional mediator in $D A G_{1,2}$, to evaluate whether the potential marginal extra mediation provided by adding adulthood lifestyle factors and financial hardship $\left(D A G_{1}\right)$ to socioeconomic positions $\left(D A G_{2}\right)$ is robust with respect to a potential confounder (possibly induced by father's occupational position). We investigated mediation modifications by sex and ran analyses on complete data to check consistency with results obtained via missing data imputation. Finally, to evaluate the chosen specification of the natural effect model, we estimated joint and path-specific effects when adding a product term between levels of counterfactual exposures in the natural effect model, and exposure/mediators product terms in the outcome imputation models. Namely, we posited the following natural effect model

$\operatorname{logit}\left[E\left\{Y\left(s, M\left(s^{*}\right)\right) \mid C\right\}\right]=\beta_{0}+\beta_{1} s+\beta_{2} s^{*}+\beta_{3} s s^{*}+\beta_{4} C$

From it, we simultaneously estimated the natural pure direct effect odds ratio as

$$
\frac{\operatorname{odd} s\left\{Y\left(s, M\left(s^{*}\right)\right)=1 \mid C\right\}}{\operatorname{odd}\left\{\left\{\left(s^{*}, M\left(s^{*}\right)\right)=1 \mid C\right\}\right.}=\exp \left\{\beta_{1}\left(s-s^{*}\right)\right\}
$$

and the natural total indirect effect odds ratio as

$\frac{\operatorname{odd} s\{Y(s, M(s))=1 \mid C\}}{\operatorname{odd} s\left\{Y\left(s, M\left(s^{*}\right)\right)=1 \mid C\right\}}=\exp \left\{\left(\beta_{2}+\beta_{3}\right)\left(s-s^{*}\right)\right\}$.

Results. Effect estimates were in the same direction and of similar magnitude to those reported in main analysis when defining heightened inflammation as CRP $>4 \mathrm{mg} / \mathrm{L}$ (vs $>3 \mathrm{mg} / \mathrm{L}$ ) (see Table $\mathrm{S} 2$ ), when excluding participants with high values of CRP (>10mg/L) (see Table S3), or participants with co-morbidities (see Table S4).

When adding co-morbidities as an additional mediator (Table S5), the marginal extra mediation of childhood SEP inequalities accounted by adding adulthood lifestyle factors and financial hardship $\left(D A G_{1}\right)$ to socioeconomic positions $\left(D A G_{2}\right)$ was similar to that reported in main analysis.

Analyses stratified by sex (Table S6) revealed that in women financial hardship and lifestyle factors mediated life-course SEPs inequalities in heightened inflammation more than in men (72\% vs $53 \%$ ). This is in line with previous research pointing to a sex disparity in the impact of life-course socioeconomic positions on adult cardiovascular risk factors and diabetes (Murray et al., 20I I; Smith et al., 20 I I) and with a similar finding reported in the cross-sectional study by Camelo et al. (20l4).

Estimation with complete data $(\mathrm{N}=3,699)$ provided results that were consistent with those reported in main analysis (see Table S7), backing the adopted imputation procedure. Finally, natural effects estimated with more complex models provided similar proportion mediated and effects compared to those reported in main analysis (Table S8). 
Alwan H, Pruijm M, Ponte B et al. Epidemiology of masked and white-coat hypertension: the familybased SKIPOGH study. PLoS One 2014;9:e92522.

Bernstein MS, Morabia A, Sloutskis D. Definition and prevalence of sedentarism in an urban population. Am J Public Health 1999:89:862-7.

Camelo LV, Giatti L, Neves JA et al. Life course socioeconomic position and C-reactive protein: mediating role of health-risk behaviors and metabolic alterations. The Brazilian Longitudinal Study of Adult Health (ELSA-Brasil). PLoS One 2014;9:e 108426.

Emerging Risk Factors Collaboration, Kaptoge S, Di Angelantonio E et al. C-reactive protein concentration and risk of coronary heart disease, stroke, and mortality: an individual participant meta-analysis. Lancet 2010;375:132-40.

Firmann M, Mayor V, Vidal PM et al. The CoLaus study: a population-based study to investigate the epidemiology and genetic determinants of cardiovascular risk factors and metabolic syndrome. BMC Cardiovasc Disord 2008;8:6.

Galobardes B, Lynch J, Davey Smith G. Measuring socioeconomic position in health research. Br Med Bull 2007;8I-82:2I-37.

Lange TS, Vansteelandt S, Bekaert M. A simple approach for estimating natural direct and indirect effects. Am J Epidemiol 20I2; 1 76:190-5.

MacKinnon DP, Dwyer JH. Estimating mediated effects in prevention studies, Eval Rev 1993; 17:14458.

Murray ET, Mishra GD, Kuh D, Guralnik J, Black S, Hardy R. Life Course models of socioeconomic position and cardiovascular risk factors: 1946 Birth Cohort. Ann Epidemiol 20 I I;2 I:589-97.

Ponte B, Pruijm M, Ackermann D et al. Reference values and factors associated with renal resistive index in a family-based population study. Hypertension 2014;63:136-42.

Rose D, Harrison E. The European socio-economic classification: A new social class schema for comparative European research. Eur Soc 2007;9:459-90.

Smith BT, Lynch JW, Fox CS et al. Life-course socioeconomic position and type 2 diabetes mellitus: The Framingham offspring study. Am J Epidemiol 20I I; I 73:438-47.

Steen J, Loeys T, Moerkerke B, Vansteelandt S. Flexible mediation analysis with multiple mediators. Am J Epidemiol 2017a; 186:184-93.

Steen J, Loeys T, Moerkerke B, Vansteelandt S. medflex: An R package for flexible mediation analysis using natural effect models. J Stat Softw 2017b;76:I-46.

Swiss Federal Statistical Office.

https://www.bfs.admin.ch/bfs/fr/home/statistiques/population/familles.html

VanderWeele TJ, Robinson WR. On the causal interpretation of race in regressions adjusting for confounding and mediating variables. Epidemiology 20I4;25:473-84. 
930 VanderWeele TJ, Vansteelandt S. Mediation analysis with multiple mediators. Epidemiol Methods $931 \quad 2014 ; 2: 95-I I 5$.

932

933 Vansteelandt S, Bekaert M, Lange T. Imputation strategies for the estimation of natural direct and 934 indirect effects. Epidemiol Methods 20 12; I:131-58.

Vansteelandt S, Daniel RM. Interventional effects for mediation analysis with multiple mediators. 937 Epidemiology 20I7;28:258-65.

938

939

940 


\section{SUPPLEMENTARY TABLES}

Table SI. Summary statistics for the SKIPOGH and CoLaus/PsyCoLaus populations. Continuous characteristics are summarized through their mean and lower/upper quartiles. Categorical characteristics are summarized through their absolute and relative (\%) prevalence. The columns titled $\mathrm{N}$ report the number of individuals and the percentage of missing data if any.

\begin{tabular}{|c|c|c|c|c|}
\hline Characteristics & SKIPOGH & $\mathbf{N}$ & CoLaus/PsyCoLaus & $\mathbf{N}$ \\
\hline $\begin{array}{c}\text { Sex } \\
\text { [woman/man] }\end{array}$ & $\begin{array}{l}548(53 \%) \\
485(47 \%)\end{array}$ & 1033 & $\begin{array}{l}2689(55 \%) \\
2192(45 \%)\end{array}$ & 4881 \\
\hline Age [years] & $5 I(36,65)$ & 1033 & $63(54,7 \mathrm{I})$ & 4881 \\
\hline $\begin{array}{c}\text { Ethnicity } \\
\text { [white/other] }\end{array}$ & $\begin{array}{c}1023(99 \%) \\
10(1 \%) \\
\end{array}$ & 1033 & $\begin{array}{c}4495(92 \%) \\
384(8 \%) \\
\end{array}$ & $4879(0.04 \%)$ \\
\hline $\begin{array}{l}\text { Father's occupational } \\
\text { position } \\
\text { [low/intermediate/high/ } \\
\text { not working] }\end{array}$ & $\begin{array}{r}266(26 \%) \\
493(48 \%) \\
245(24 \%) \\
4(0.4 \%) \\
\end{array}$ & $1008(2 \%)$ & $\begin{array}{c}1229(29 \%) \\
1708(40 \%) \\
1268(30 \%) \\
42(1 \%) \\
\end{array}$ & 4247 (I3\%) \\
\hline $\begin{array}{l}\text { Highest attained education } \\
\text { [compulsory/vocational/ } \\
\text { high-school/university] }\end{array}$ & $\begin{array}{l}114(12 \%) \\
340(35 \%) \\
153(16 \%) \\
359(37 \%) \\
\end{array}$ & $966(6 \%)$ & $\begin{array}{r}832(17 \%) \\
1715(36 \%) \\
702(15 \%) \\
1557(32 \%) \\
\end{array}$ & $4877(0.1 \%)$ \\
\hline $\begin{array}{c}\text { Occupational position } \\
\text { [low/intermediate/high/ } \\
\text { not working] }\end{array}$ & $\begin{array}{l}|7|(18 \%) \\
53 \mid(57 \%) \\
190(20 \%) \\
47(5 \%)\end{array}$ & $939(9 \%)$ & $\begin{array}{r}1182(24 \%) \\
1972(40 \%) \\
632(13 \%) \\
1091(22 \%)\end{array}$ & $4876(0.1 \%)$ \\
\hline $\begin{array}{c}\text { Financial difficulties } \\
\text { [yes/no] }\end{array}$ & $\begin{array}{l}107(11 \%) \\
899(89 \%)\end{array}$ & $1006(3 \%)$ & $\begin{array}{r}671(16 \%) \\
3567(84 \%) \\
\end{array}$ & 4238 (I3\%) \\
\hline $\begin{array}{c}\text { Heightened inflammation } \\
\text { [yes/no] }\end{array}$ & $\begin{array}{l}160(16 \%) \\
861(84 \%)\end{array}$ & $1021(1 \%)$ & $\begin{array}{r}781(19 \%) \\
3417(81 \%) \\
\end{array}$ & 4198 (14\%) \\
\hline $\begin{array}{c}\text { Smoking status } \\
\text { [current/former/never } \\
\text { smoker] }\end{array}$ & $\begin{array}{l}232(24 \%) \\
306(31 \%) \\
437(45 \%)\end{array}$ & 975 (6\%) & $\begin{array}{r}882(21 \%) \\
1632(38 \%) \\
1775(41 \%) \\
\end{array}$ & 4289 (12\%) \\
\hline $\begin{array}{c}\text { Body mass index } \\
\text { [obese/overweight/normal/ } \\
\text { underweight] }\end{array}$ & $\begin{array}{c}127(13 \%) \\
308(31 \%) \\
5 \mid 4(52 \%) \\
33(3 \%)\end{array}$ & $982(5 \%)$ & $\begin{array}{c}704(16 \%) \\
1664(39 \%) \\
1856(43 \%) \\
60(1 \%)\end{array}$ & $4284(12 \%)$ \\
\hline $\begin{array}{c}\text { Alcohol intake } \\
\text { [high/moderate/abstainer] }\end{array}$ & $\begin{array}{l}|3|(\mid 14 \%) \\
456(47 \%) \\
374(39 \%)\end{array}$ & 961 (7\%) & $\begin{array}{c}284(7 \%) \\
2990(69 \%) \\
1060(24 \%)\end{array}$ & 4334 (II\%) \\
\hline $\begin{array}{c}\text { Physical activity } \\
\text { [sedentary/active] }\end{array}$ & $\begin{array}{l}365(38 \%) \\
597(62 \%)\end{array}$ & $962(7 \%)$ & $\begin{array}{l}2078(57 \%) \\
1562(43 \%)\end{array}$ & 3640 (25\%) \\
\hline $\begin{array}{l}\text { Prevalent diabetes } \\
\text { [yes } / \mathrm{no}]\end{array}$ & $\begin{array}{c}26(3 \%) \\
955(97 \%)\end{array}$ & $981(5 \%)$ & $\begin{array}{r}438(10 \%) \\
3896(89 \%)\end{array}$ & 4334 (II\%) \\
\hline $\begin{array}{c}\text { History of stroke or } \\
\text { coronary heart diseases } \\
\text { [yes } / \text { no] }\end{array}$ & $\begin{array}{c}25(3 \%) \\
958(97 \%)\end{array}$ & $983(5 \%)$ & $\begin{array}{c}305(7 \%) \\
3998(93 \%)\end{array}$ & 4303 (12\%) \\
\hline $\begin{array}{c}\text { Co-morbidities } \\
\text { [yes/no] }\end{array}$ & $\begin{array}{c}50(5 \%) \\
930(95 \%)\end{array}$ & $980(5 \%)$ & $\begin{array}{r}687(16 \%) \\
3590(84 \%)\end{array}$ & 4277 (I2\%) \\
\hline
\end{tabular}


Table S2. Odds ratio (OR) and $95 \%$ confidence intervals $(\mathrm{Cl})$ for effects estimated through the natural effect model when participants with $\mathrm{CRP}>4 \mathrm{mg} / \mathrm{L}$ are declared with heightened inflammation. The average population size across imputation and bootstrap draws was $N=5,105$ and $N=4,|7|$ for the effects of father's occupational position (low vs high) and life-course accumulation of disadvantaged socioeconomic positions (highest vs lowest score), respectively. PM is proportion mediated (ratio of the indirect and total effect OR logarithm).

\section{Parameter estimates}

OR $[95 \% \mathrm{Cl}]$

\begin{tabular}{|c|c|}
\hline Total effect of father's occupational position & $1.8[1.4,2.3]$ \\
\hline Direct effect $\mathrm{DAG}_{1}$ & $1.4[1.1,1.8]$ \\
\hline Joint indirect effect $\mathrm{DAG}_{1}$ & I.3 [I.I, I.4]; PM = $42[21,77] \%$ \\
\hline Direct effect $\mathrm{DAG}_{2}$ & $1.6[1.2,2.0]$ \\
\hline Joint indirect effect $\mathrm{DAG}_{2}$ & I.I $[1.0,1.2] ; P M=22[8,47] \%$ \\
\hline $\begin{array}{l}\text { Mediation through educational attainment } \\
S \rightarrow M_{1} Y\end{array}$ & $\mathrm{PM}=19[4,40] \%$ \\
\hline $\begin{array}{l}\text { Partial mediation through occupational position } \\
S->M_{2}->Y\end{array}$ & $P M=3[-2,12] \%$ \\
\hline Total effect of accumulation score & $2.8[2.0,4.1]$ \\
\hline Direct effect $\mathrm{DAG}_{3}$ & $1.6[1.2,2.4]$ \\
\hline Joint indirect effect $\mathrm{DAG}_{3}$ & I.7 $[1.5,2.0] ; P M=53[37,79] \%$ \\
\hline
\end{tabular}

Table S3. Odds ratio $(\mathrm{OR})$ and $95 \%$ confidence intervals $(\mathrm{Cl})$ for effects estimated through the natural effect model when participants with high values of CRP $(>10 \mathrm{mg} / \mathrm{L})$ are excluded. The average population size across imputation and bootstrap draws was $\mathrm{N}=4,08 \mathrm{I}$ for the effect of life-course accumulation of disadvantaged socioeconomic positions (highest vs lowest score). PM is proportion mediated (ratio of the indirect and total effect OR logarithm).

\begin{tabular}{l|l}
\multicolumn{1}{c|}{ Parameter estimates } & \multicolumn{1}{c}{ OR $[95 \% \mathrm{Cl}]$} \\
\hline & $2.1[1.7,2.9]$ \\
\hline Total effect of accumulation score & $1.3[1.0,1.8]$ \\
\hline Direct effect $\mathrm{DAG}_{3}$ & $1.6[1.5,1.8] ; \mathrm{PM}=66[45,93] \%$ \\
\hline Joint indirect effect DAG &
\end{tabular}

Table S4. Odds ratio (OR) and $95 \%$ confidence intervals $(\mathrm{Cl})$ for the effect of life-course accumulation of disadvantaged socioeconomic positions (highest vs lowest score) on heightened inflammation in adulthood estimated through the natural effect model when participants with co-morbidities were removed. The average population size across imputation and bootstrap draws was $\mathrm{N}=3,70 \mathrm{I}$. PM is proportion mediated (ratio of the indirect and total effect OR logarithm).

Parameter estimates

OR $[95 \% \mathrm{CI}]$

Total effect of accumulation score

$2.6[1.8,3.5]$

Direct effect DAG

$1.6[1.1,2.1]$

Joint indirect effect $\mathrm{DAG}_{3}$

$1.6[1.5,1.8] ; \mathrm{PM}=53[37,82] \%$


Table S5. Odds ratio (OR) and $95 \%$ confidence intervals $(\mathrm{Cl})$ for the effect of father's occupational position (low vs high) on heightened inflammation in adulthood estimated through the natural effect model when comorbidities were added as an additional mediator. The average population size across imputation and bootstrap draws was $\mathrm{N}=5,105$. PM is proportion mediated (ratio of the indirect and total effect OR logarithm).

\begin{tabular}{|c|c|}
\hline Parameter estimates & OR $[95 \% \mathrm{Cl}]$ \\
\hline Total effect of father's occupational position & $1.5[1.3,1.8]$ \\
\hline Direct effect DAG & $1.2[1.0,1.4]$ \\
\hline Joint indirect effect DAG & I.3 [1.2, I.4]; PM = $57[36,87] \%$ \\
\hline Direct effect $\mathrm{DAG}_{2}$ & $1.3[1.1,1.6]$ \\
\hline Joint indirect effect $\mathrm{DAG}_{2}$ & I.I $[1.1,1.2] ; P M=32[17,71] \%$ \\
\hline
\end{tabular}

Table S6. Odds ratio (OR) and $95 \%$ confidence intervals $(\mathrm{Cl})$ for the sex specific effect of the life-course accumulation of disadvantaged socioeconomic positions (highest vs lowest score) on adulthood heightened inflammation estimated through the natural effect model. The average population size across imputation and bootstrap draws was $\mathrm{N}=2,12 \mathrm{I}$ and $\mathrm{N}=2,049$ for women and men respectively. PM is proportion mediated (ratio of the indirect and total effect OR logarithm).

\section{Parameter estimates}

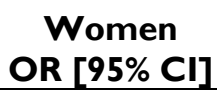
$2.7[2.0,4.0]$

Total effect of accumulation score

Direct effect $\mathrm{DAG}_{3}$

Joint indirect effect $\mathrm{DAG}_{3}$
$1.3[1.0,2.0]$

$2.0[1.7,2.4]$

$\mathrm{PM}=72[49,97] \%$

\section{Men \\ OR $[95 \% \mathrm{Cl}]$}

Table S7. Odds ratio (OR) and $95 \%$ confidence intervals $(\mathrm{Cl})$ for the effect (low vs high) of father's occupational position and adulthood heightened inflammation estimated through the natural effect model with complete data $(\mathrm{N}=3,699)$. PM is proportion mediated (ratio of the indirect and total effect OR logarithm).

\begin{tabular}{l|l}
\multicolumn{1}{c|}{ Parameter estimates } & \multicolumn{1}{c}{ OR $[95 \% \mathrm{Cl}]$} \\
\hline Total effect of father's occupational position & $1.6[1.3,2.1]$ \\
\hline Direct effect DAG & $1.3[1.0,1.6]$ \\
\hline Joint indirect effect DAG 1 & $1.3[1.2,1.4] ; \mathrm{PM}=53[30,90] \%$ \\
\hline
\end{tabular}

$2.0[1.5,3.1]$

$1.4[1.0,2.2]$

I.5 [1.3, I.7]; $\mathrm{PM}=53[28,89] \%$ 
Table S8. Odds ratio (OR) and $95 \%$ confidence intervals $(\mathrm{Cl})$ for effects estimated through the natural effect model specified with a product term between levels of counterfactual exposure. The ORs were estimated with an outcome imputation model specified with product terms between exposure and mediators on the multiplicative scale. The average population size across imputation and bootstrap draws was $\mathrm{N}=5,105$ and $\mathrm{N}=4$, I7I for the effects of father's occupational position (low vs high) and life-course accumulation of disadvantaged socioeconomic positions (highest vs lowest score), respectively. PM is proportion mediated (ratio of the indirect and total effect OR logarithm).

Parameter estimates

OR $[95 \% \mathrm{Cl}]$

\begin{tabular}{|c|c|}
\hline Total effect of father's occupational position & $\mathrm{I} .5[\mathrm{I} .3, \mathrm{I} .8]$ \\
\hline Pure direct effect $D_{A A}$ & $\mathrm{I} .2[\mathrm{I} .0, \mathrm{I} .5]$ \\
\hline Joint total indirect effect $\mathrm{DAG}_{1}$ & $\mathrm{I} .2[\mathrm{I} . \mathrm{I}, \mathrm{I} .4] ; \mathrm{PM}=50[23,83] \%$ \\
\hline Pure direct effect $D A_{2}$ & $\mathrm{I} .3[\mathrm{I} . \mathrm{I}, \mathrm{I} .7]$ \\
\hline Joint total indirect effect $\mathrm{DAG}_{2}$ & $\mathrm{I} . \mathrm{I}[\mathrm{I} .0, \mathrm{I} .2] ; \mathrm{PM}=32[3,7 \mathrm{I}] \%$ \\
\hline $\begin{array}{l}\text { Mediation through educational attainment } \\
S->M_{1} Y\end{array}$ & $P M=28[3,66] \%$ \\
\hline $\begin{array}{l}\text { Partial mediation through occupational position } \\
S \rightarrow>M_{2}->Y\end{array}$ & $\mathrm{PM}=4[-7,20] \%$ \\
\hline Total effect of accumulation score & $2.3[1.7,3.0]$ \\
\hline Pure direct effect $\mathrm{DAG}_{3}$ & $1.4[1.0,1.9]$ \\
\hline Joint total indirect effect $\mathrm{DAG}_{3}$ & $1.6[1.4,1.9] ; P M=59[38,93] \%$ \\
\hline
\end{tabular}

